\title{
SMITH PREDICTOR IN RELAY AUTOTUNING
}

\author{
KORBEL, J[iri]
}

\begin{abstract}
This contribution is focused on utilization of the Smith predictor in the automatic control design method. The first phase consists from the biased relay experiment where the unknown parameters of the low order controlled system with time delay are identified. The following control design is based on the algebraic methods through a general solution of Diophantine equations in the ring of proper and stable rational functions. The time delay term is neglected in the control design because the control loop contains a model of the controlled system which was identified by the relay experiment.
\end{abstract}

Key words: algebraic design, relay autotuning, Smith predictor

\section{INTRODUCTION}

Most processes in industry are controlled by PID controllers. The proper setting of their parameters is still the subject of research of many authors. The first tuning rule which was presented by authors Ziegler - Nichols uses an empiric table which is based on critical parameters of the controlled system. Unfortunately, it has many limitations and drawbacks. Other solution how to choose the PID parameters is the automatic tuning. Development of various principles was started by (Åström \& Hägglund, 1984). Many authors studied and improved this principle over the next years (Majhi \& Atherton, 1998; Morilla et al., 2000; Hang et al., 2002). Autotuning is also provided in many present commercial PID controllers.

The next problem in the control of industrial processes is the presence of time delay which causes instability of the feedback control loop. There is a set of principles how to approximate or eliminate the time delay term. One of them is control loop with the model of controlled system which is called Smith predictor.

This contribution is focused on automatic tuning of controller for low order systems with time delay. The parameters of the controlled system are identified by the biased relay with hysteresis (Prokop et al., 2010). The following control design is made in the ring of proper and stable rational functions through the general solution of Diophantine equations. Time delay term is neglected in the control design. The control loop consists of the standard feedback loop with the model of controlled system.

\section{RELAY IDENTIFICATION}

The estimation of the process or ultimate parameters is a crucial point in all autotuning principles. The relay feedback test can utilize various types of relay for the parameter estimation procedure. The classical relay feedback test (Åström and Hägglund, 1984) proposed for stable processes a symmetrical relay without hysteresis. Asymmetrical relays with or without hysteresis bring further progress. After the relay feedback test, the estimation of process parameters can be performed. A typical data response of such feedback relay experiment is depicted in Fig. 1.

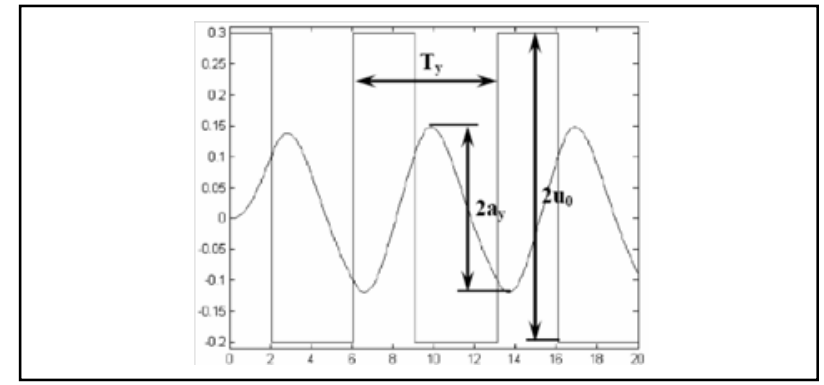

Fig. 1. Relay feedback output

After the experiment, the controlled system is approximated by the first order transfer function with time delay term (Vítečková \& Víteček, 2004) in the form:

$$
G(s)=\frac{K}{T s+1} \cdot e^{-\Theta s}
$$

\section{ALGEBRAIC DESIGN METHOD}

Controller parameters are computed by general solution of Diophantine equations in the ring of proper and stable rational functions; see e.g. (Vidyasagar, 1987; Kučera, 1993).

$$
\begin{aligned}
& G(s)=\frac{b(s)}{a(s)}=\frac{\frac{b(s)}{(s+m)^{n}}}{\frac{a(s)}{(s+m)^{n}}}=\frac{B(s)}{A(s)} \\
& n=\max (\operatorname{deg}(a), \operatorname{deg}(b)), \quad m>0
\end{aligned}
$$

All feedback stabilizing controllers are given by a general solution of the Diophantine equation:

$$
A P+B Q=1
$$

which can be expressed with $Z$ free in $\mathrm{R}_{\mathrm{PS}}$ :

$$
\frac{Q}{P}=\frac{Q_{0}-A Z}{P_{0}+B Z}
$$

Final control aim is not only the stability of control loop but also the asymptotic reference tracking, disturbance rejection and other specifications. These requirements are expressed through divisibility conditions by choosing the arbitrary element $Z$.

\section{SMITH PREDICTOR}

Time delay very deteriorates stability of the control loop when it is present in controlled system. One possibility how to compensate the time delay is the control loop with the model of the controlled system which is called Smith predictor. The scheme of the loop in depicted in Fig. 2. 


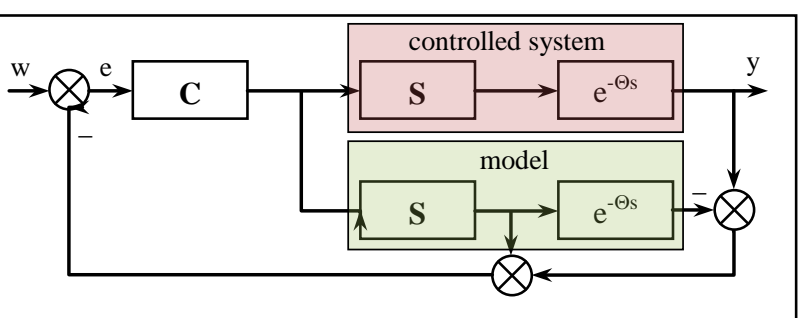

Fig. 2. Smith predictor

Transfer function of the control loop in Fig. 2 is described by the relation (Balátě, 2003):

$$
G_{w}(s)=\frac{Y(s)}{W(s)}=\frac{G_{C}(s) \cdot G_{S}(s) \cdot e^{-\Theta s}}{1+G_{C}(s) \cdot G_{S}(s)}
$$

As can be seen the denominator of (5) is exactly the same as for systems without time delay. When both controlled system and model are the same, the time delay is eliminated.

\section{SIMULATION EXAMPLES}

Example 1: Second order controlled system with time delay was identified (Vítečková \& Víteček, 2004; Prokop et al., 2010) in the form of first order transfer function with time delay:

$$
G(s)=\frac{1}{(2 s+1)^{2}} \cdot e^{-2 s} \quad \tilde{G}(s)=\frac{0.98}{3.46 s+1} \cdot e^{-2.77 s}
$$

The controller was designed for the identified system with time delay term neglected. For the tuning parameter $m=0.22$ the controller is:

$$
C(s)=\frac{0.51 s+0.17}{s}
$$

The original system G(s) from (6) was controlled by (7) in two different control loops. A standard feedback control loop was used in the first place and after it also Smith predictor. The control responses can be seen in Fig. 3.

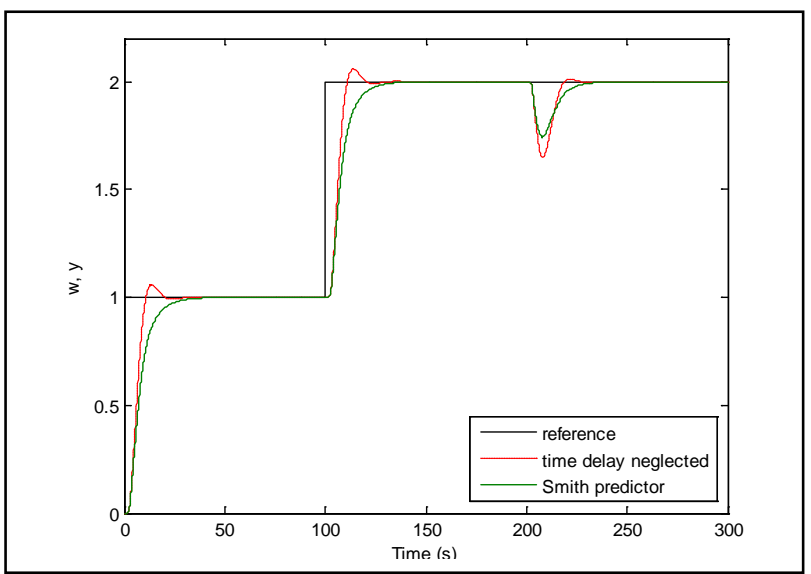

Fig. 3. Control responses (Example 1)

Example 2: Fifth order system with time delay was identified in the form of first order transfer function with time delay:

$$
G(s)=\frac{3}{(2 s+1)^{5}} \cdot e^{-5 s} \quad \tilde{G}(s)=\frac{2.99}{5.88 s+1} \cdot e^{-10.35 s}
$$

The controller was designed for the identified system with time delay term neglected. For parameter $\mathrm{m}=0.13$ the controller is:

$$
C(s)=\frac{0.17 s+0.03}{s}
$$

The control responses are depicted in Fig. 4. As can be seen, the response in standard feedback control loop has considerable oscillations. However, the response with Smith predictor in the loop is aperiodic.

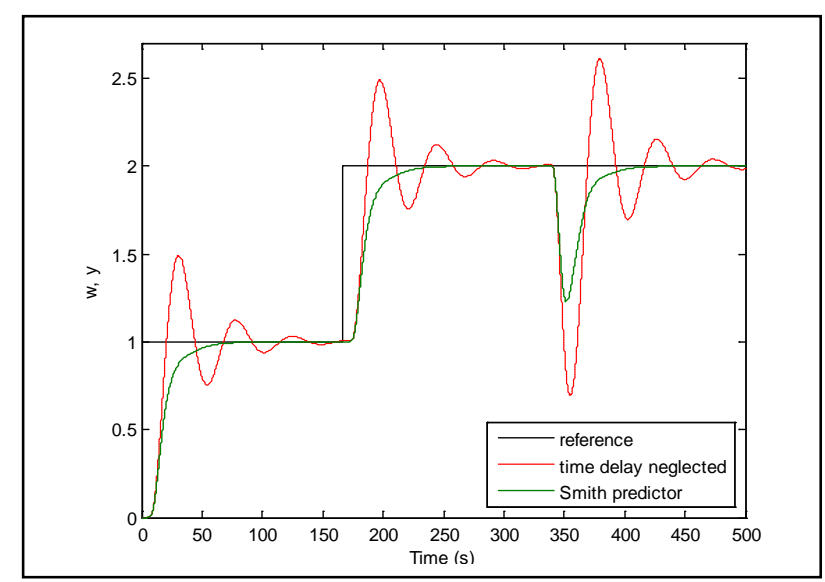

Fig. 4. Control responses (Example 2)

\section{CONCLUSION}

This paper presented another combination of biased relay identification of controlled system and subsequent control design. The unknown parameters of the controlled system were identified as the first order transfer function with time delay. Unlike the previous contributions a Smith predictor was used in the control loop. The simulations confirmed that control response was considerably improved even the model parameters were not the same as controlled system.

\section{ACKNOWLEDGMENT}

This work was supported by the Ministry of Education, Youth and Sports of the Czech Republic under the Research Plan No. MSM 7088352102 and by the European Regional Development Fund under the project CEBIA-Tech No. CZ.1.05/2.1.00/03.0089.

\section{REFERENCES}

Åström, K.J. \& Hägglund, T. (1984). Automatic tuning of simple regulators with specification on phase and amplitude margins. Automatica, Vol.20, pp.645-651

Balátě, J. (2003). Automatické řizení. Praha: BEN-technická literatura, 663 s. ISBN 80-7300-020-2

Hang, C.C.; Åström, K.J. \& Wang, Q.C. (2002). Relay feedback auto-tuning of process controllers - a tutorial review, Journal of Process Control, Vol.12, No.6

Kučera, V. (1993). Diophantine equations in control - A survey, Automatica, Vol. 29, No. 6, pp. 1361-75

Majhi, S. \& Atherton, D.P. (1998). Autotuning and controller design for unstable time delay processes, In: Preprints of UKACC Conf an Control, pp. 769-774

Morilla, F.; Gonzáles, A. \& Duro, N. (2000). Auto-tuning PID controllers in terms of relative damping, In: Preprints of IFAC Workshop PID’00, pp. 161-166

Prokop, R.; Korbel, J. \& Prokopová, Z. (2010). Relay feedback autotuning - a polynomial design approach, In: Preprints of 24th European Conference on Modelling and Simulation, Nicosia, pp. 290-295

Vidyasagar, M. (1987). Control system synthesis: a factorization approach. MIT Press, Cambridge, M.A.

Vítečková, M. \& Víteček, A. (2004). Experimentální identifikace metodou relé (in Czech), In: Automatizácia a informatizácia 